\section{Determinants of HIV/AIDS in armed conflict populations}

\author{
Danvas Omare, Amar Kanekar \\ Department of Health Studies, East \\ Stroudsburg University of Pennsylvania, \\ USA
}

\section{Abstract}

More than 40 million people worldwide have been infected with human immunodeficiency virus (HIV) since it was first reported in 1981. Over 25 million of these have lost their lives to the disease. Most of the studies related to HIV/AIDS have been conducted in stable populations across the globe. Few of these studies have been devoted to displaced populations, particularly those in areas of conflict. Displaced populations that are forced to leave their homes in most cases find themselves in unfamiliar territories, often poor and hungry. Many of them become refugees and internally displaced people (IDPs). The objective of this review was to address a number of different social determinants of HIV/AIDS in displaced populations in areas of conflict. A comprehensive review of peer reviewed literature published in English between 1990 and 2010 obtained through an open search of PUBMED database using key words such as HIV and war, HIV/AIDS and conflict, AIDS and security was conducted. Twelve different studies that looked at the implications of HIV/AIDS in conflict or displaced populations were retrieved. The review revealed that there were various factors influencing conflict and HIV/AIDS such as forced population displacement, breakdown of traditional sexual norms, lack of health infrastructure, and poverty and powerlessness of women and children. Social determinants of increased HIV/AIDS prevalence in displaced populations are scarcity of food, poverty, insecurity of displaced populations and gender power differentials.

\section{Introduction}

The devastation effects of HIV/AIDS continue to be felt all over the world as individuals get infected. More than 40 million people worldwide have been infected with human immunodeficiency virus (HIV) since it was first reported in 1981 and over 25 million of these have lost their lives to the disease. In $2007,35 \%$ of all HIV infections occurred in Africa, which is the home of over $67 \%$ of all people living with AIDS worldwide. ${ }^{1}$ It is also estimated that AIDS has orphaned over 13 mil- lion children with many of them losing one or both parents in Sub-Saharan Africa alone and the number could be higher. With the spread of HIV increasing in other areas of the world such as East Asia and Eastern Europe, the epidemic will continue to have profound demographic, economic, governance and social implications for generations to come. ${ }^{2}$ The disease has had effects on almost every economy in Africa in particular and in many other parts of the world. For every ten adult men infected with HIV in Africa, about fourteen adult women are also infected, with young women between the ages of 15-24 being the most vulnerable. ${ }^{3}$ In Swaziland for example, the AIDS scourge has reduced the life expectancy to 37 years according to the United Nations Development Program 2007 report.

\section{Relationship between conflict and HIV/AIDS}

Until recently, the epidemiology of HIV/AIDS and other sexually transmitted infections (STIs) has not been considered in armed conflict settings. ${ }^{2}$ There have not been large-scale studies that have quantitatively analyzed the relationship between conflict and HIV/AIDS. Data collection ceases usually with the start of any conflict as everyone flees those areas and populations shift, which explains why there is limited data on this issue. In 2004 for instance, of more than 10,000 abstracts published for the international AIDS conference in Bangkok Thailand, only one reported on the treatment of AIDS in a conflict setting.

Many countries around the world have experienced armed conflict, which is defined as open armed clashes between two or more centrally organized parties with continuity between the clashes in disputes about power over government territory. ${ }^{5}$ By the year 2004, there were 25 active conflicts worldwide and refugee movements affected sixty-nine countries with forty-eight countries having internally displaced people. ${ }^{6}$ It is estimated that millions of people get trapped in areas of conflict and as conflict progresses their needs increase, requiring the attention of the international community. The United Nations High Commissioner for Refugees reported that 40 million people were displaced worldwide by the end of $2002{ }^{5}$

Conflicts come with unprecedented challenges such us the spread of HIV and food shortage. These challenges make the fleeing people destitutes. The challenges particularly the health ones are magnified, as people often have no access to healthcare services either because the systems providing such services have collapsed as a result of the conflict or do not exist in the first place. Many times those displaced find themselves in new areas far
Correspondence: Dr. Amar Kanekar, Department of Health Studies, East Stroudsburg University of Pennsylvania, 200 Prospect Street, East Stroudsburg, PA, 18301-2999, USA.

Tel. +1.570.4223702 - Fax: +1.570.4223848

E-mail: akanekar@po-box.esu.edu

Key words: HIV/AIDS, conflict, security, internally displaced people, refugees.

Contributions: D0, manuscript writing; AK, structuring the manuscript as a review of literature, revising the manuscript.

Conflict of interest: the authors report no conflicts of interest.

Received for publication: 12 October

Accepted for publication: 22 December 2010.

This work is licensed under a Creative Commons Attribution 3.0 License (by-nc 3.0)

(C) Copyright D. Omare and A. Kanekar., 2011 Licensee PAGEPress, Italy

Journal of Public Health in Africa 2011; 2:e9 doi:10.4081/jphia.2011.es

from their homes, such as refugee camps. These new surroundings may not have existing systems to provide such services. Even when such systems exist, the number of displaced people looking for services may ovewhelm them and even lead to their breakdown. ${ }^{7}$ If populations being displaced have high prevalence of HIV infections, conflict may change the distribution patterns and this may become a security threat not only in those areas of conflict but also to the entire world, as refugees are relocated in many parts of the globe.

\section{Materials and Methods}

The current study identifies the determinants of HIV/AIDS (Human Immunodeficiency Virus/Acquired Immunodeficiency Syndrome) in armed conflict populations using a narrative review format. This review is a secondary analysis using PUBMED database. The review search employed is an open search of PUBMED database. The inclusion criteria used for extracting articles were i) articles published in English language between 1990 and 2010; ii) articles extracted using keywords such as HIV and war, HIV/AIDS and conflict, AIDS in displaced populations, AIDS and security. The exclusion criteria were i) articles published prior to 1990 and ii) articles published in languages other than English. A total of 12 articles were retrieved and analyzed in this study. 


\section{Results}

The current narrative review illustrates very interesting findings in terms of variety of determining factors for getting HIV/AIDS in armed conflict populations. These determining factors range from showing a deterministic positive relationship between conflict and high HIV rates, ${ }^{1}$ to violence against women giving rise to increased incidence of HIV/AIDS. ${ }^{8}$ Some of the significant findings from this review point towards importance of violence, ${ }^{8,9}$ breakdown of health systems, ${ }^{2}$ drugs and trafficking of sex workers, ${ }^{10,11}$ and incorrect reporting by media. ${ }^{12}$ These results clearly established a poignant role of structural determinants as stabilizing influences on the spread of HIV/AIDS among various populations and subpopulations in conflict areas. A summary of the result of the current review is presented in Table 1.

\section{Discussion}

\section{Factors influencing conflict}

Several factors have been identified as possible contributors to increased chances of being exposed to HIV infection in armed conflict including forced population displacement. ${ }^{5}$ During armed conflict, many people are forced to flee the fighting and this may take them away from their home or usual residential locale. HIV, like any other infection spreads from one person to another, and will follow the movement of people and as the displaced people move from one place to another so does the infection trends of HIV. ${ }^{1}$ As people flee conflict, many social networks are destroyed or disrupted and those institutions that normally protect and support people cease to exist. Many people do not have time to access safer sex tools like condoms, which may be scarce under war circumstances. The result is that many end up engaging in risky sexual behaviors without any regard to the consequences. ${ }^{7}$ Breakdown of traditional sexual norms can also play a big role in HIV transmission rates in armed conflict situations. Armed conflict brings a lot of chaos, which breaks the traditional values and norms regarding sexual behaviors. This can contribute to an overall increase in the risk of HIV exposure.

\section{Women and children, conflict and HIV/AIDS}

The vulnerability of women and young girls to HIV infection during and after armed conflict is well known. ${ }^{4}$ Conflict causes conditions of poverty, severe deprivation and powerless- ness that force women and young girls in particular to engage in 'exchange sex' to survive. ${ }^{7}$ In such situations the women and young girls are powerless and cannot negotiate safer sex practices. Their vulnerability is exacerbated due to their destitution, displacement, discrimination and reduction of basic services and coping mechanisms. ${ }^{12}$

In refugee camps and other areas of settlement, women may gain some form of independence but when they return home postconflict, they find themselves dealing with realities of pre-conflict norms, where men dominated everything. It was on the backdrop of this issue that the UN adopted resolutions 1308 and 1325 recognizing the vulnerability to HIV infection of women and young girls in armed and post conflict setting. ${ }^{16}$ The declaration of the UN general Assembly special session on HIV/AIDS, in 2001 clearly indicates that refuges have to be protected by the host countries and that their well being must be addressed. ${ }^{17}$ Unfortunately, this is not the case in many countries that host refugees, as many are relocated to remote areas of the host countries that are not accessible and live in horrible conditions. Many of the host countries do not have enough resources to begin with and an influx of refugees into such poor economies only makes matters worse as hostilities develop between the refugees and the local populations of the host countries. In a bid to survive, women and girls resort to commercial sex, which increases the risk of HIV prevalence in these populations..$^{5}$ Also, the threat of partner violence may reduce women willingness to refuse sexual relations in conflict situations. ${ }^{18}$ Even without conflict, women use transactional sex for survival in many parts of the developing world and are thus likely to use it in areas of conflict. ${ }^{3}$

In many countries where there is armed conflict, rape is used as a weapon of war and the fighting groups rape many women and girls in areas under their control. The young men fighting in these conflicts abduct women and rape them as an initiation, especially for the newly recruited armies. In northern Uganda for example, a rebel group, the Lord's Resistance Army (LRA) has been fighting the Ugandan army for more than 21 years and the war has been characterized by child abductions and frequent rapes, attacks on civilian camps, physical disfigurement and ruthless killings. ${ }^{9}$ Over 60,000 children have been abducted and forcibly conscripted to fight as rebel soldiers in northern Uganda. ${ }^{14}$ According to the UNAIDS, rape as a weapon has been documented in many areas of conflict such as a Bosnia-Herzegovina, the Democratic Republic of Congo (DRC), Liberia and during the Rwandan genocide. ${ }^{7} \mathrm{~A}$ good number of uniformed personnel are HIV positive and their involvement in sexual contracts with refugees only exacerbates the HIV transmission in such populations.

Acts of violence against women are recognized as gross violations of human rights and have been identified by criminal law and public health as a cause and a consequence of the spread of HIV/AIDS among women and girls. ${ }^{8}$ The Human Rights Watch has documented war crimes, including astonishing accounts of the use of sexual violence as a weapon of war with all its life-long consequences for the women involved. ${ }^{15}$ Violence is the worst form of gender inequality and is the direct result of gender norms that make male violence against women a socially acceptable way to control an intimate partner. ${ }^{3}$ As many as $47 \%$ of the Rwandan women were raped during the genocide which claimed millions of Rwandan people. ${ }^{8}$ In West Africa, during Sierra Leone's 10 year Civil war, $9 \%$ of women were sexually assaulted with young girls being raped systematically by the fighting groups. Young girls abducted in wars were forced into sexual slavery as wives assigned to rebel commanders, where they suffered serial rape that resulted in pregnancy and an elevated risk of HIV infection both for them and their newborns. ${ }^{14}$

\section{Health infrastructure, conflict and HIV/AIDS}

Functioning health infrastructures are very crucial in the fight against any disease. Where they are lacking, diseases abound including HIV/AIDS and the results are usually seen in the overall mortality rates. So, whenever conflicts arise in any country, many systems breakdown, and those supposed to maintain them become victims of violence themselves. For example the civil war in Angola that lasted 27 years led to the breakdown of all forms of health structures outside the capital Luanda and by the year 2005 the health system remained collapsed. ${ }^{19}$ Very few operational health centers and hospital are in operation today and with the lack of water supply and sanitation the country has one of the highest rates of infant mortality in the world. In Nepal, one of the poorest countries in the world, a bloody conflict between the communist party (Maoist) and government forces since 1996 has led to widespread destruction of infrastructure and disruption of the flow of essential supplies. ${ }^{11}$ The seasonal migration and sexual trafficking across a porous border with India, fuelled by the war has led to an increase in the HIV prevalence in that region of India where well over 200, 000 Nepalese women work in brothels as sex workers. Blood supply safety is no longer guaranteed in such areas, and there is a lack of HIV/AIDS prevention services, which has lead to an increased HIV transmission rate. ${ }^{11}$ 


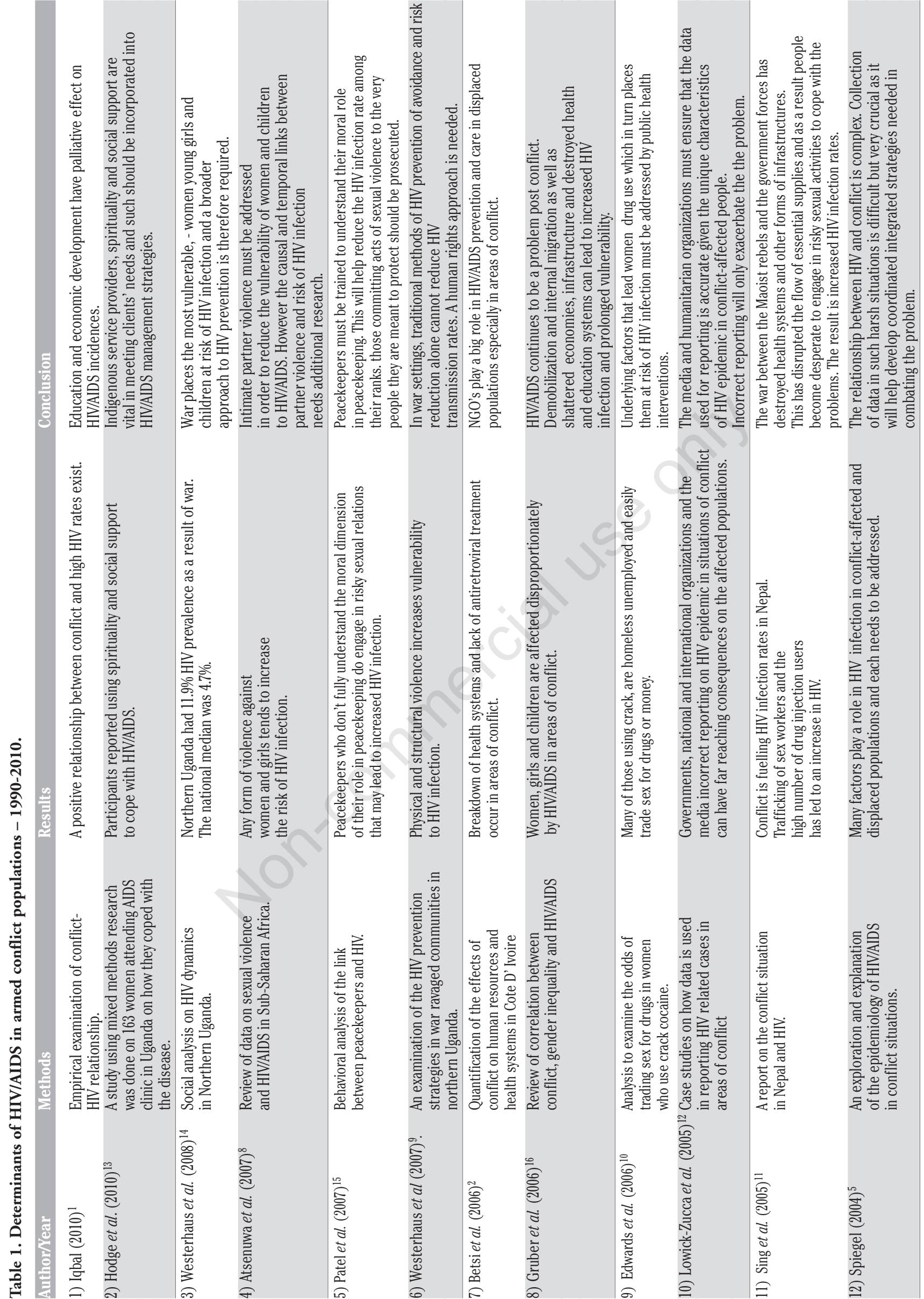




\section{Soldiers, conflict and HIV/AIDS}

The words of General Romeo Dallaire, chief of the UN mission in Rwanda 1993-1994, that there is no consensual sex between soldiers and the local population in a war or conflict zone, brought to light what many peacekeepers are capable of doing in areas of conflict. ${ }^{15}$ Soldiers and peace keepers are away from their homes and families for long periods of time. Geographical separation disrupts their social discipline that would normally prevail in their homes and families. The result is their engagement in risky sexual behaviors, consensual or non-consensual leading to high HIV prevalence in those localities. ${ }^{7}$ This sexual conduct of humanitarian actors during peacekeeping missions put many individuals at risk of contracting HIV. ${ }^{15}$ There are over 50 million people serving in the military both in uniform and in civilian capacities around the world, with many of them deployed to areas of armed conflict. The HIV prevalence in this population can impact the HIV status of displaced populations, especially when they are involved in sexual exploitation of refugees as was the case in Kosovo and West Africa. ${ }^{18}$

\section{Coping with conflict situations}

Conflict situations can be very stressful to displaced populations and coping with such can be very difficult, especially when people are forced to leave their homes. Individuals resort to different coping strategies. While some engage in indiscriminate sex with multiple partners, sex trade and violence, many turn to alcohol, crude and illicit drugs while others resort to the use of crack and other drugs as part of their coping strategies. ${ }^{3,10}$ Those drugs that are ingested, sniffed or smoked may not be available due to conflict, as the routes may be disrupted making displaced people turn to injectable ones where syringes and needles are shared. ${ }^{7}$ These risky behaviors have been known to increase the rate of HIV transmission among injection drug users in the general population.

\section{Conclusions}

The HIV/AIDS crisis has reached epidemic proportions and globally women and children bear a large brunt of this disease. With many countries becoming politically unstable, there has been an increase in the number of armed conflicts that have led to the removal and displacement of people, with many ending up being refugees while others become IDPs. HIV/AIDS is not just a health issue, its effects spread beyond health. It affects human rights and development as well as social and gender relations. It has disrupted families when combined with conflict and has left millions of orphans exposed to untold suffering. There is a great need for global leaders to come together and join their efforts in the fight for curbing this pandemic and its effects.

This review studied various published articles addressing HIV/AIDS in conflict situations. Research reports, published abstracts from conference proceedings, monographs, thesis and dissertations, which addressed this topic were excluded from this review.

\section{Implications for future}

Implications for future can be summarized as follows: i) international community should come together to design strategies that can provide HIV/AIDS services to displaced populations, not only in times of conflict but also in times of disasters and other emergencies; ii) training programs that are aimed at sensitizing uniformed personnel globally should be developed and administered to peacekeepers; iii) this review has identified various structural determinants for HIV/AIDS in armed conflict populations such as gender power differentials, health infrastructure, poverty and social destabilization. Structural interventions addressing these determinants, which are selfsustaining nationally and internationally should be put in place; iv) as there is a dearth of literature on this topic of HIV/AIDS in conflict situations future reviews should be more comprehensive including research reports, monographs, published conference abstracts and articles published in different languages addressing this poignant topic.

\section{References}

1. Iqbal Z, Zorn C. Violent conflict and the spread of HIV/AIDS in Africa. J Polit 2010;72:149-62.

2. Betsi NA, Koudou BG, Cisse G, et al. Effect of conflict on human resources and health systems in Cote d'Ivoire: Prevention of and care of people with HIV/AIDS. AIDS Care 2006;18:356-65.

3. Pope C, White RT, Malow R. HIV/AIDS. Global frontiers in prevention/intervention. 2009, Routledge Publ., New York, NY, USA.

4. Ellman T, Culbert H, Torres-Feced V. Treatment of AIDS in Conflict-affected settings: a failure of imagination. Lancet 2005;386:278-80.

5. Spiegel PB. HIV/AIDS among conflictaffected and displaced populations:
Dispelling myths and taking action. Disasters 2004;28:322-39.

6. Spiegel PB, Bennedsen A. The epidemiology of HIV among conflict-affected and displaced populations: Current Concept. In: C. Pope, RT White and R. Malow (eds.). HIV/AIDS. Global frontiers in prevention/intervention. 2009, Routledge Publ., New York, NY, USA, pp 395-402.

7. UNAIDS. Focus - AIDS and conflict: a growing problem worldwide. 2004 Report on the AIDS Global Epidemic. 2004, pp 175181.

8. Atsenuwa A, Aniekwu NJ. Sexual violence and HIV/AIDS in Sub-Saharan Africa: An intimate Link. Local Environment 2007;12: 313-24.

9. Westerhaus MJ, Finnegan AC, Zabulon Y, Mukherjee JS. Framing HIV prevention discourse to encompass the complexities of war in northern Uganda. Am J Public Health 2007;97:1184-6.

10. Edwards JM, Halpern CT, Wechsberg WM. Correlates of exchange sex for drugs or money among women who use crack cocaine. AIDS Educ Prev 2006;18:420-9.

11. Sing S, Mills E, Honeyman S, et al. 2005. HIV in Nepal: Is the violent conflict fuelling the epidemic? PLoS Med 2005;2: e216.

12. Lowicki-Zucca M, Spiegel P, Ciantia F. AIDS, conflict and the media in Africa: Risks in reporting data badly. Emerging Themes in Epidemiology 2005;2:12.

13. Hodge RD, Roby LJ. Sub-Saharan African Women living with HIV/AIDS: An exploration of general and spiritual coping strategies. Soc Work 2010:55:27-37.

14. Westerhaus MJ, Finnegan AC, Zabulon Y, Mukherjee JS. Northern Uganda and paradigms of HIV prevention: The need for social analysis. Glob Public Health 2008;3: 39-46.

15. Patel P, Tripodi P. Peacekeepers, HIV and the role of masculinity in military behavior. Int Peacekeep 2007;14:584-98.

16. Gruber J. Does conflict increase vulnerability to HIV infection? Issues for research agenda. Afr J AIDS Res 2006:5:1:41-8.

17. UNAIDS. The UN strategic plan for HIV/ADS - 2001-2005. Available at: http://data.unaids.org/Governance/PCB03/ pcb_11_01_03_1_en.pdf

18. Romero L, Walleestein N, Licero J, et al. Woman to Woman: Coming to together for positive change-using empowerment and popular education to prevent HIV in women. AIDS Educ Prev 2006;18:390-405.

19. Flechner D. A human rights approach to protecting people living with HIV/AIDS in Angola. Int Soc Sci J 2005;57:627-36. 